\title{
The Valuation of Geothermal Power Projects in Indonesia Using Real Options Valuation
}

\author{
Reza A. Bilqist, M. Dachyar*, and Farizal \\ Industrial Engineering Department, Universitas Indonesia
}

\begin{abstract}
Geothermal power project should be carefully evaluated, because not only the project is large-scale and high-risk, but also huge investments are needed to make the project profitable. The purpose of this study is to evaluate and analyze the present value of the geothermal power plant projects in Indonesia using net present value and real options valuation approach to obtain better project value that indicates profitable investments. Project value determined based on Net Present Value (NPV). The Monte Carlo Simulation calculated NPV based on discount rate, production volume, and operation and maintenance (O\&M) cost. The risk of the project defined with 3 scenarios to obtain NPV and calculate Expected Net Present Value (ENPV). The result of this study showed Real Options Valuation obtained the highest project value indicating a higher return of the project that was previously undervalued using NPV and ENPV. Real Options Valuation approach improved the project value by incorporating scenario analysis and strategic option in the valuation process.
\end{abstract}

\section{Introduction}

Renewable energy in Indonesia only $6.2 \%$ of the total energy mix in 2015 that indicating Renewable energy in Indonesia reached $6.2 \%$ of the total energy mix in 2015 that indicating Indonesia has a large dependence on fossil energy [1]. Meanwhile, Indonesia has a great potential for renewable energy such as geothermal. Geothermal power generation is a promising substitute for the traditional-generating approaches like fossil energy [2]. Geothermal Power Plant that has been installed in Indonesia only $1640 \mathrm{MW}$ about $4.9 \%$ of 29,544 MW total potential geothermal in Indonesia [1]. However, geothermal power generation should be carefully evaluated, because not only the project is large-scale and highrisk, but also huge investments are needed to make the project profitable.

\section{Literature Review}

Renewable energy power generation is a large-scale and high-risk project [3]. Uncertainty in a project of renewable energy power generation, have to take into consideration regarding their economic viability, which is linked to several uncertain variables that affect the evolution of the cash flows [4]. Valuation enables investors to determine asset value and take

\footnotetext{
*Corresponding author: mdachyar@yahoo.com
} 
into consideration unlimited possible scenarios, as well as limiting losses in unfavorable scenarios. Valuation and redesigning business process are several methods that used in a project in order to get the best result or profit $[5,6]$, especially in a high-risk project such as oil and gas energy [7], and photovoltaic energy [8].

Geothermal is one of renewable energy project with huge potential, especially in Indonesia [9]. Maintenance management also affects operational activities in power generation, without proper management of operation and maintenance can lead to high costs in operating and maintenance activities and affect company performance [10]. Therefore, the value of the project must be evaluated financially to determine whether the project profitable or not, the main idea of valuation is to determine the financial value that closely resembles the true value of an asset or project [11].

Net Present Value or Discounted Cash Flow (DCF) is a traditional and simple valuation method, where incremental cash inflows and outflows for each period discounted and projected to present time when investment is made [12]. NPV methods assume that the investment is an all or nothing strategy and do not account for managerial flexibility that exists such that management can alter the course of an investment over time when certain aspects of the project's uncertainty become known (Mun, 2005). Project value has an important function as the basis of capital budgeting and is related to resource allocation to long-term project investments [13].

In the NPV approach, cash inflows and outflows are estimated over the life time of the project and are subsequently discounted to the present time. Meanwhile in Expected Net Present Value (ENPV), a number of scenarios are generated. The NPV for each of the envisaged project outcomes are determined and the ENPV is calculated by taking the sum of the product of the different NPVs and the probability of their occurrence [6].

The basic option theory in finance is a contract giving the buyer the right, but not the obligation, to buy or sell an underlying asset as stock or index, at a specific price on or before a certain date [14]. Real Options Valuation (ROV) refers to application of the option theory to the assessment of non-financial or "real" investments with learning and flexibility, such as multi-stage $\mathrm{R} \& \mathrm{D}$, manufacturing plant expansion [15]. A project that can be terminated after a technical failure is an example of a real option. Initiation of a project generates the option, not the obligation, to continue the project [6].

Real Options Valuation not only enables investors to increase an asset value, due to the consideration of an unlimited number of possible future scenarios, as well as limiting losses in unfavorable scenarios, but also the most adequate when researches consider uncertainty scenarios aligned with managerial flexibility and the use of this approach can significantly change the value of an asset [16]. The implementation of Real Options Valuation were widely used in high risk project such as product development portfolio [15], oil and gas [7], mining $[12]$, photovoltaic energy $[3,16]$, wind energy $[17,18,19]$, water energy $[20,21]$, and nuclear [22].

Monte Carlo simulation utilized to obtain better actual value estimation of a particular project [11]. The Monte Carlo Simulation stands out because it enables the generation of a great variety of scenarios as well as multiple uncertainties [16]. As all those scenarios produce associated results, each scenario can have a forecast.

\section{Methodology}

The investment project is a geothermal power generation project in Sumatera with total capacity is $236 \mathrm{MW}$. The project divided into 2 units power plant, the Unit-1 power plant with $92 \mathrm{MW}$ capacity and duration of project 10 years, the Unit-2 power plant with $144 \mathrm{MW}$ project started after Unit-1 is successfully installed and power generated with duration of project is 8 years. After Unit-1 power plant started to operate for 8 years, the investors have 
right to defer or abandon the project Unit-2 power plant project if Unit-1 power plant had indicated not profitable. To determine the volatility of the projects, we must analyze the uncertainties that affect it. The uncertainties considered in this renewable energy project are discount rate, electric sales volume, and Operation and Maintenance (O\&M) cost.

The project estimated with uniform sales volume derived from estimated electric produced and uniform Operation and Maintenance (O\&M) cost. The electricity price on the basis of a feed-in tariff under the government's constant benchmarking is 13.8 cents $\$ / \mathrm{KWh}$. Simple NPV analysis conducted to calculate project value based on Unit-1 and Unit-2 installed. The Monte Carlo Simulation conducted with 1000 trials to generate multiple project value using uncertain variables that influenced the project. The uncertain variables are discount rate, sales volume, and O\&M cost.

In ENPV approach, three scenarios were generated in Unit-2 power plant project, which created based on the worst scenario, normal scenario, and best scenario of the Unit-2 project. The probability of occurrence for worst, normal, and best scenario is $20 \%, 50 \%$, and $30 \%$ respectively.

The right to invest, defer, and abandon the Unit-2 power plant project become Real Options that must be considered in project valuation. The investors have the option to wait or defer investing until a later date for Unit-2 power plant project. That is, wait until uncertainty becomes resolved and then decide on the next course of action afterwards.

Investments will be made in the Unit-2 project if conditions indicate a good scenario and decide to abandon the project if the market condition is akin to normal or worst case scenario. In this study, Passive Wait and See Strategy were applied where we decide to wait one year assuming that we will gather more valuable information within time frame, and then decide to execute the project.

\section{Result and Discussion}

\subsection{The Results of Monte Carlo Simulation for NPV, ENPV and ROV}

The simulation results of NPV model for Unit-1 and Unit-2 power plant presented in Fig 1. Fig 1 showed the mean NPV for Unit-1 and Unit-2 is $\$ 92.25$ million. The probability that Unit-1 project will break even or have NPV will be $>0$ is $63.3 \%$ rather significantly increased compared to Unit-1 project executed.

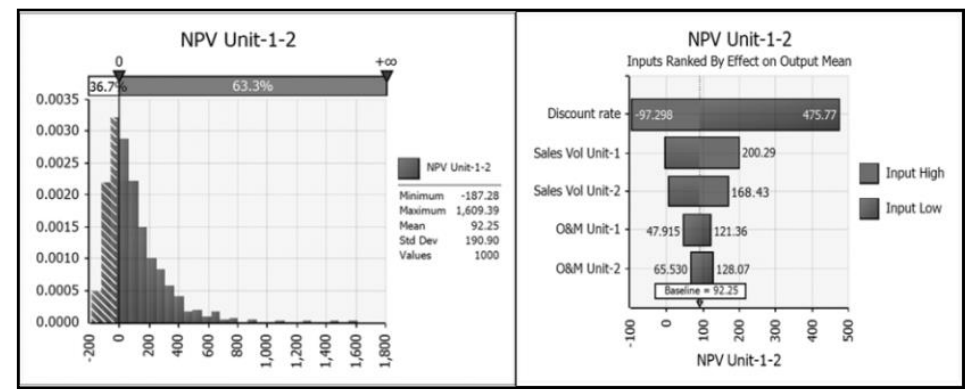

Fig 1. NPV simulation result and sensitivity chart for Unit-1 and Unit-2 projects

The NPV sensitivity chart after Monte Carlo Simulation shows that the Unit-1 and Unit2 project is sensitive to the discount rate variation. The simulation results of ENPV model for Unit-1 and Unit-2 power plant presented in Fig 2. Fig 2 showed the mean NPV for Unit1 and Unit-2 is $\$ 93.62$ million. The probability that Unit-1 and Unit-2 project will break even or have NPV will be $>0$ is $64.6 \%$. In ENPV model, distribution is less wide compared to 
NPV model. This comparison can be seen in Fig 1 where range of value NPV model is $-\$ 187$ million to $\$ 1609$ million, but in Fig 2 of ENPV model the range of value is $-\$ 173$ million to $\$ 1458$ million.

The NPV sensitivity chart after Monte Carlo Simulation shows that the Unit-1 and Unit2 project is sensitive to the discount rate variation. The simulation results of Unit-1 and Unit2 power plant using ROV best scenario presented in Fig 3. Fig 3 showed the mean project value for Unit-1 and Unit-2 is \$130.86 million. The NPV sensitivity chart after Monte Carlo Simulation of ROV best scenario shows that the Unit-1 and Unit-2 project is sensitive to the discount rate variation.

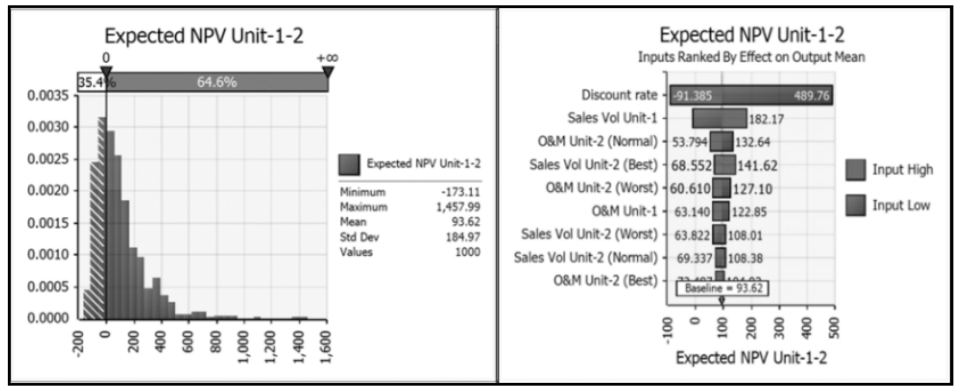

Fig 2. ENPV simulation result and sensitivity for Unit-1 and Unit-2 projects

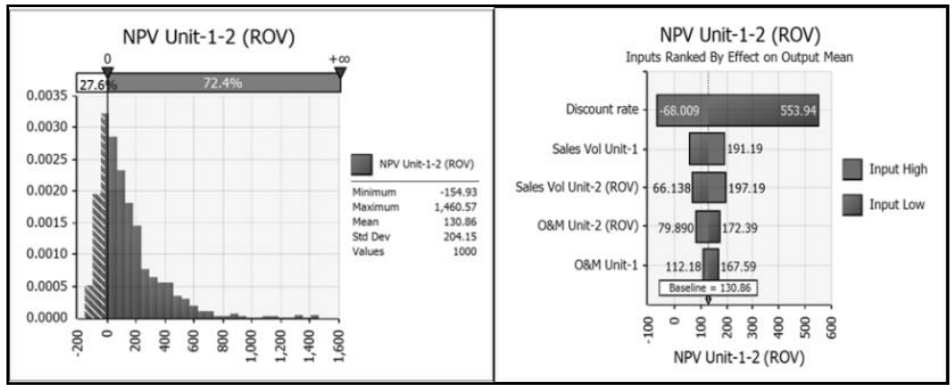

Fig 3. ROV simulation result of best scenario and sensitivity chart for Unit-1 and Unit-2 projects

\subsection{Analysis for Monte Carlo Simulation}

The result of Monte Carlo Simulation for NPV, ENPV and ROV presented as overlay graphical chart in Fig 4. Fig 4 shows ENPV approach obtained rather similar result with NPV, but ENPV provides a much tighter distribution although not really significant. Once we added ROV approach where we only execute the Unit-2 project if the best condition obtained, the risk has been reduced and the return of the project increased.

Based on the result obtained from NPV method through ROV method, we can define risk as uncertain variables that fluctuate in project value. All risks are mitigated in ROV approach since we do not execute the project if the worst or normal case scenario occurs. In this study also obtained that geothermal project really sensitive to discount rate and sales volume. Real Options approach enhanced project value since the project executed when the best case scenario occurs. This decision creates better valuation simply by having the right strategic optional available, acting appropriately, and valuing the project in terms of its "real" value, which includes this opportunity to make midcourse corrections when new information becomes available. 


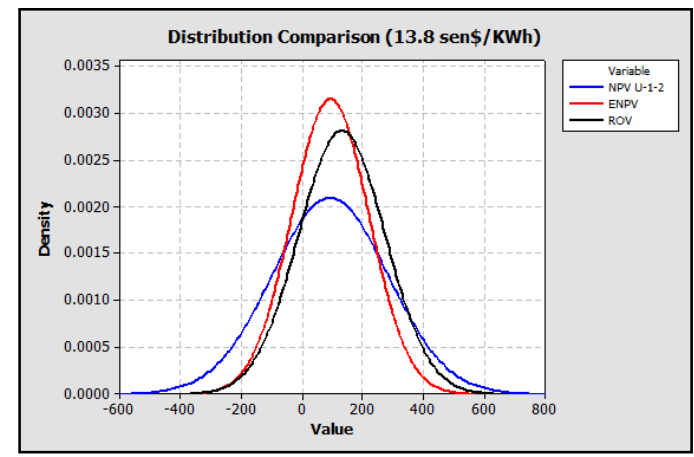

Fig 4. Overlay distributional comparison of NPV, ENPV, and ROV

\section{Conclusions}

This study showed that the valuation of geothermal power generation project using NPV method underestimates the value of the project rather than ROV. The ROV method assesses projects based on options in the implementation of a project. In ROV approach where we only executed the project if best scenario occurred, we obtain better value of the project and risk has been reduced. The result of the study showed discount rate is the most sensitive variable in the project followed by sales volume.

Since ROV applied option mechanism, which allows companies or investors achieve better overview and flexible management for project valuation. Therefore, ROV can help investor or companies to consider an option framework in the decision-making process. That is, to find strategic options that exist in projects or to create strategic options in order to increase the project's value.

\section{References}

1. Ditjen EBTKE, (2016)

2. N. A. Pambudi, Renewable and Sustainable Energy R. 81, 2893-2901, (2018).

3. L. Tian, J. Pan, R. Du, W. Li, and G. Qibing, J. of App Energy 201, 354-362, (2017)

4. M. M. Barroso and J. B. Iniesta, Energy Policy 55, 335-352, (2013).

5. M. Dachyar and G. Novita, ARPN J. of Eng \& App Sci 11, 4539-4546,( 2016).

6. B. J. A. Willigers and T. L. Hansen, J. of R\&D Mgmt 38, 520-537, (2008).

7. J. Guedes and P. Santos, Energy Economics 60, 377-386, (2016).

8. K. Kim, S. Kim and H. Kim, IOP Conf. Series 40, 1-8, (2016).

9. M. P. Hochstein and S. Sudarman, Geothermics 37, 220-266, (2008).

10. M. Dachyar and Y. Tohir, ARPN J. of Eng \& App Sci 13, 2571-2580, (2018).

11. J. Mun, Real Option Analysis Tools and Techniques, (John Wiley \& Sons, New Jersey, (2005).

12. N. A. Gardner, McGill University Annal, (2015).

13. M. Tsui, Valuing Innovative Technology $R \& D$ as a Real Option, (MIT, Boston, 2005).

14. M. Amram and N. Kulatilaka, Real options: managing strategic investment in an uncertain world, (Harvard Business School Press, Boston, 1999)

15. M. Jin and X. Tian, JIEM 8, 72-84, (2015). 
16. G. Esteves and I. Leite, IEEE Xplore, 1-6, (2017).

17. D. Loncar, I. Milovanovic, B. Rakic and T. Radjenovic, Renew \& Sustain Energy Rev 75, 354-367, (2017).

18. M. M. Barroso and J. B. Iniesta, Journal of Energy 77, 422-433, (2014).

19. D. Angelopoulos, R. Bruckmann, F. Jirous, I. Konstantinaviciute, P. Noothout, J. Psarras, L. Tesniere and B. Breitschopf, Energy \& Environment 27, 82-104, (2016).

20. K. Kim, H. Park and H. Kim, Renew \& Sustain Energy Reviews 75, 918-926, (2017).

21. J. Marques, M. Cunha, D. Savic and O. Giustolisi, Procedia Eng 89, 856-863, (2014).

22. L. Tian, H. Shan and N. Zhu, Energy Procedia 104, 299-304, (2016). 